\title{
Locally Advanced Unresectable Digestive System Neuroendocrine Neoplasm
}

National Cancer Institute

\section{Source}

National Cancer Institute. Locally Advanced Unresectable Digestive System

Neuroendocrine Neoplasm. NCI Thesaurus. Code C158090.

A digestive system neuroendocrine neoplasm that has spread from its original site of growth to nearby tissues or lymph nodes and is not amenable to surgical resection. 